Sharif University of Technology
Scientia Iranica
SCIENTIA
IRAN ICAA
http://scientiairanica.sharif.edu

\title{
Determining shear capacity of ultra-high performance concrete beams by experiments and comparison with codes
}

\author{
M. Pourbaba ${ }^{\mathrm{a}}$ and A. Joghataie ${ }^{\mathrm{b}, *}$ \\ a. Department of Civil Engineering, Sharif University of Technology, International Campus, Kish Island, Iran. \\ b. Department of Civil Engineering, Sharif University of Technology, Tehran, Iran.
}

Received 16 May 2017; received in revised form 8 July 2017; accepted 7 August 2017

\author{
KEYWORDS \\ Ultra-High \\ Performance \\ Fiber-Reinforced \\ Concrete (UHPFRC) \\ beams; \\ Shear strength; \\ Steel fibers; \\ Regulations; \\ Experiment to \\ predicted shear \\ strength.
}

\begin{abstract}
In this research, 19 specimens of ultra-high performance fiber-reinforced concrete rectangular beams were made and their shear resistance was determined experimentally. The results were compared with estimations by ACI 318, RILEM TC 162TDF, Australian guideline, and Iranian national building regulations. To compare the code estimations, the ratio of experimental shear strength to predicted shear strength was calculated for each code. This ratio is in fact a measure of safety factor on the one hand and a measure of precision of the estimation on the other hand. Based on the results of both studies, the authors concluded that the Australian guideline, with the amount of 2.5, provided the minimum experimental to predicted ratio, while the Iranian National Building Regulations, with the amount of about 10, provided the highest one. The ratios obtained by ACI and RILEM were about 8 and 3.6, respectively. The Iranian and ACI codes basically provided the same strength estimation. Both were very conservative, which might mainly be because the codes were dubious about the precision of their own estimations. However, RILEM and Australian codes estimated the shear resistance with reasonable margin of safety.
\end{abstract}

(C) 2019 Sharif University of Technology. All rights reserved.

\section{Introduction}

Experimental investigations into shear failure of reinforced concrete beams without transverse reinforcement illustrate that the shear behavior of these beams is complex. More specifically, the recent research on High-Strength Concrete (HSC) and Ultra-High Performance Fiber-Reinforced Concrete (UHPFRC) beams emphasizes their quite complex behavior [1-5].

The shortcomings of UHPC, such as low tensile

\footnotetext{
*. Corresponding author.

E-mail addresses: mpourbaba@yahoo.com (M. Pourbaba); joghatae@sharif.edu (A.Joghataie).
}

doi: $10.24200 /$ sci. 2017.4264 strength and low ductility, along with other excellent characteristics, such as ultra-high compressive strength, have led to the development of UHPFRC in the developed countries. This is made possible by adding steel fiber to concrete (UHPFRC). The combination of two advanced materials, namely, steel fibers and UHPC, leads to many advantages, e.g., increase in UHPC tensile strength and ductility of the fibers, which provides noteworthy resistance against the initiation of cracks. This has led to the development of more slender structural elements and hence, saving of materials and energy. The inherent qualities of UHPFRC, such as high compressive strength, suitable ductility, and ideal tension strength, have made it more suitable for application in special structures and their elements $[2,6]$. 
Investigation into different mechanical characteristics and properties of UHPFRC as well as its potentials, in order to replace conventional concrete, has recently attracted the attention of a large number of researchers [3-5,7]. Among these many properties, those relevant to structural design have been relatively more frequently investigated. Researchers have focused on the compressive and tensile strength, modulus of elasticity, Poisson's ratio, creep, and shrinkage [7]. Furthermore, a large number of studies on UHPC have concentrated on flexural [8-11] and shear behaviors in this development [12-18].

Currently, the fact is that shear failure is difficult to predict accurately. This difficulty is more particularly observed in high-strength concrete and UHPFRC beams. In spite of many decades of experimental research, some of which was reviewed above, and the use of highly sophisticated analytical tools, practically accurate enough methods and equations for estimating shear capacity are not fully understood yet. More particularly, there is no adequate knowledge about rectangular UHPFRC beams without stirrups.

In fact, the previous experimental and theoretical studies were mainly concentrated on UHPFRC beams with pre-stressing strands and, basically, I-shaped and P-shaped beams. [19-22]. Taking this gap into account, the present paper seeks to study the shear strength of rectangular UHPFRC beams with longitudinal tension rebar and without transverse reinforcement, for which the estimations of different guidelines, regulations, and codes are compared with the results obtained by recent experiments [23].

\section{Materials and methods}

\subsection{Specimens and parameters}

Nineteen beam specimens were made at the laboratories of Tabriz University, Iran, and Florida International University, US. The beams were of 3 different sizes and their dimensions were $152 \times 152 \times 559$, $102 \times 203 \times 559$, and $152 \times 76 \times 559 \mathrm{~mm}$. The materials of specimens consisted in Portland cement, fine sand, silica fume, superplasticizer, steel fibers, and water for UHPFRC; straight high-strength steel fiber (with the length of $13 \mathrm{~mm}$, diameter of $0.18 \mathrm{~mm}$, and specified tensile strength of $2700 \mathrm{MPa}$ ) for fibers; and deformed steel bars for longitudinal steel with specified yield points of about $400 \mathrm{MPa}(60 \psi)$ and $690 \mathrm{MPa}(100 \psi)$. The mix design and curing process of specimens were detailed in a previous study by the first author [23], which is also explained briefly here. Nine beams were cast from one batch of UHPC in Tabriz using the above-mentioned materials. In order to make the project economical, local materials and a conventional concrete mixer were used. The mixer was reinforced by adding steel plates inside the drum. Moreover, since
UHPC required increased energy input compared to conventional concrete, the mixing time was increased. To ensure that the UHPC did not overheat during mixing and to make the process more convenient, the temperature of the constituents was lowered and a mixture of ice and water was used, instead of water alone. As recommended by Graybeal, first, silica fume was mixed with all the sand for approximately 5 minutes $[3,5]$. Then, before adding water, cement and ground quartz were added and dry mixed for at least 5 minutes. Then, in order to improve flowability, superplasticizer was added gradually. After a number of trials, a water-cement ratio $(w / c)$ of 0.24 was obtained for the final mixture. Straight high-strength steel fiber was added by $6.1 \%$ of the weight in order to improve the mechanical properties of concrete, especially in terms of tensile strength and ductility. The superplasticizer used was AURAMIX 4450 (FOSROC), which was a polycarboxylic ether based superplasticizer.

While the 9 beams were made using generic mix of local material in Tabriz, a commercial product, known as Ductal ${ }^{\circledR}$ (similarly including cement, silica fume, ground quartz, and sand), was used in Miami to make specimens with a $w / c$ of 0.20 and steel fiber of $6.4 \%$ by weight. The rest of the process, including mixing procedure in Miami, was similar to that in Tabriz.

Cubes of $100 \times 100 \times 100 \mathrm{~mm}$ and cylinders of 100 $\times 200 \mathrm{~mm}$ specimens were also made to determine the compressive strength of UHPFRC. The specimens were kept under water in Tabriz, and in the laboratory with almost constant temperature in Miami (because of high humidity). The compressive strengths were obtained to be $125 \mathrm{MPa}$ and $137 \mathrm{MPa}$ for the specimens in Tabriz and Miami, respectively. Figures 1 and 2 show the mixing process in Tabriz and Miami. It should be noted that, as Graybeal reported, cube specimens $(100 \times 100 \mathrm{~mm})$ had compressive strengths about $5 \%$ higher than the cylinder specimens $(100 \times 200 \mathrm{~mm})$, so

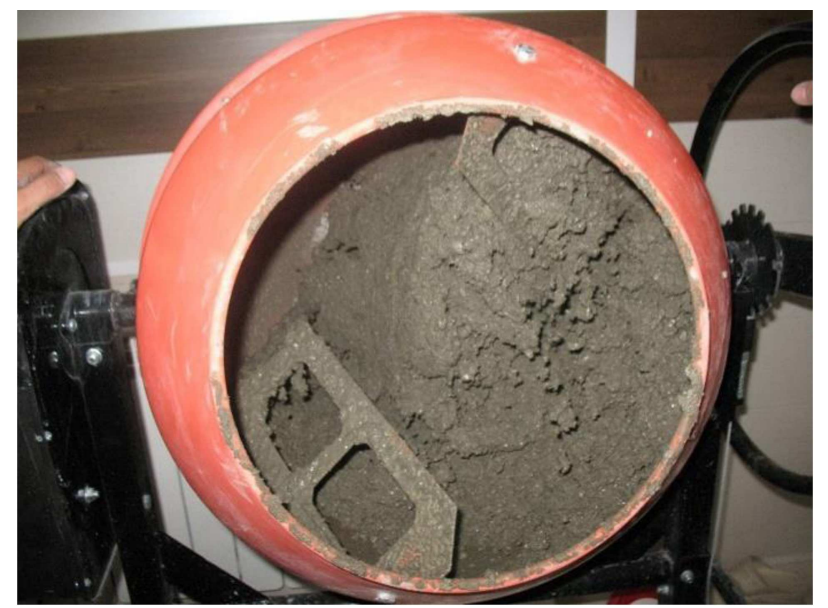

Figure 1. Drum strengthened by plate used for UHPFRC mixing in Tabriz (Iran). 


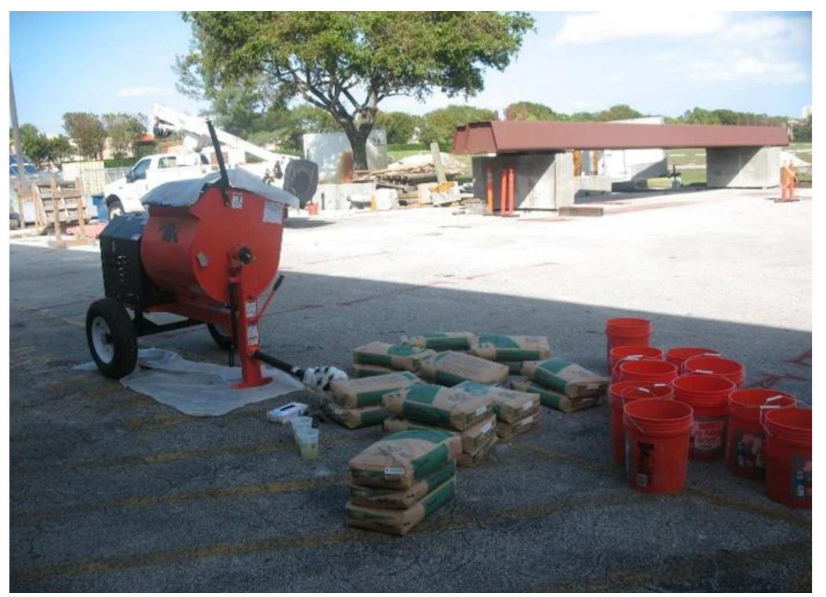

Figure 2. Site with equipment used for UHPFRC mixing in Miami (US).

the compressive strengths obtained for cube specimens were reduced by $5 \%$ [4].

The shear strength of each of the 19 specimens was determined by 4-point loading test at the laboratories of Tabriz University and Florida International University. Also, the shear strength of each specimen was estimated using various codes and regulations including ACI 318, RILEM TC 162-TDF, Australian guideline, and Iranian National Building Regulations, as will be explained in the next sections. To assess the estimation capability of the codes and regulations, the ratio of experimental shear strength to predicted shear strength (EP) was calculated. This ratio, EP, was used to compare the codes.

Table 1 provides the information about the prop- erties of specimens tested by Pourbaba [23]. All the beams were $559 \mathrm{~mm}$ in total length, having a span of $457 \mathrm{~mm}$. While the widths of specimens were only 152 and $102 \mathrm{~mm}$, they had different total depths of 152, 203, and $76 \mathrm{~mm}$. Also, given that different size bars were used, the effective depth of reinforcement was also different from specimen to specimen. The effective depths were about 126, 180, and $55 \mathrm{~mm}$. As indicated in Table 1, the longitudinal reinforcements included $3 \varnothing 25,3 \varnothing 22,3 \varnothing 20,3 \varnothing 19,3 \varnothing 18,2 \varnothing 20,2 \varnothing 16$, $3 \varnothing 14,3 \varnothing 12$, and $3 \varnothing 10$. Figure 3 shows the threedimensional view and bar placement of the specimens. It is worth mentioning that the specimens used in the above-mentioned research contained no transverse reinforcing bars.

Figure 4 presents the test setup designed for the experiments explained in Pourbaba's dissertation [23]. As shown in Figure 4, the shear span was $a=153 \mathrm{~mm}$ (203-51) for all the specimens; however, the ratio of shear span to depth, $a / d$, was different for different specimens.

\subsection{Review of various codes, regulations, guidelines, and design methods}

\subsubsection{ACI 318 (building code requirements for structural concrete, American concrete institute)}

ACI Code presents the basic shear equations in terms of shear forces, not shear stresses. In fact, in order to obtain the total shear forces, the average shear stresses are multiplied by the effective beam areas. The shear strength of the concrete, denoted by $V_{c}$, is obtained by

Table 1. Properties of tested UHPC beams by Pourbaba [23]*.

\begin{tabular}{ccccccccc}
\hline Name & $\begin{array}{c}\text { Section } \boldsymbol{b} \times \boldsymbol{h} \\
(\mathbf{m m})\end{array}$ & $\begin{array}{c}\text { Rebars } \\
(\mathbf{s})\end{array}$ & $\begin{array}{c}\boldsymbol{d} \\
(\mathbf{m m})\end{array}$ & $\begin{array}{c}\boldsymbol{A}_{\boldsymbol{s}} \\
\left(\mathbf{m m}^{2}\right)\end{array}$ & $\begin{array}{c}\boldsymbol{f}_{\boldsymbol{c}}^{\prime} \\
(\mathbf{M P a})\end{array}$ & $\begin{array}{c}\boldsymbol{f}_{\boldsymbol{y}} \\
(\mathbf{M P a})\end{array}$ & $\boldsymbol{\rho}$ & $\boldsymbol{a} / \boldsymbol{d}$ \\
\hline $\mathrm{B}^{* *}$ & $152 \times 152$ & $3 \varnothing 25$ & 125 & 1473 & 137 & 690 & 0.078 & 1.2 \\
$\mathrm{~B}^{* *}$ & $152 \times 152$ & $3 \varnothing 22$ & 126 & 1473 & 137 & 690 & 0.060 & 1.2 \\
$\mathrm{~B}^{* *}$ & $152 \times 152$ & $3 \varnothing 25$ & 125 & 1473 & 137 & 414 & 0.078 & 1.2 \\
$\mathrm{~B}^{* *}$ & $152 \times 152$ & $3 \varnothing 22$ & 126 & 1473 & 137 & 414 & 0.060 & 1.2 \\
$\mathrm{~B} 5^{* *}$ & $152 \times 152$ & $3 \varnothing 19$ & 128 & 1473 & 137 & 414 & 0.044 & 1.2 \\
$\mathrm{~B} 21$ & $152 \times 152$ & $3 \varnothing 20$ & 127 & 942.5 & 125 & 400 & 0.049 & 1.2 \\
$\mathrm{~B} 22$ & $152 \times 152$ & $3 \varnothing 18$ & 128 & 763.4 & 125 & 400 & 0.039 & 1.2 \\
$\mathrm{~B} 23$ & $152 \times 152$ & $3 \varnothing 20$ & 127 & 942.5 & 125 & 400 & 0.049 & 1.2 \\
$\mathrm{~B} 24$ & $152 \times 152$ & $3 \varnothing 18$ & 128 & 763.4 & 125 & 400 & 0.039 & 1.2 \\
B29 & $102 \times 203$ & $2 \varnothing 20$ & 178 & 628.3 & 125 & 400 & 0.035 & 0.9 \\
$\mathrm{~B} 30$ & $102 \times 203$ & $2 \varnothing 16$ & 180 & 402.1 & 125 & 400 & 0.022 & 0.8 \\
$\mathrm{~B} 35$ & $152 \times 76$ & $3 \varnothing 14$ & 54 & 461.8 & 125 & 400 & 0.056 & 2.8 \\
$\mathrm{~B} 36$ & $152 \times 76$ & $3 \varnothing 12$ & 55 & 339.3 & 125 & 400 & 0.040 & 2.8 \\
$\mathrm{~B} 37$ & $152 \times 76$ & $3 \varnothing 10$ & 56 & 235.6 & 125 & 400 & 0.027 & 2.7 \\
\hline
\end{tabular}

* Based on data from Pourbaba's dissertation [23].

** These specimens were tested in duplicates $(a$ and $b)$ in Miami to confirm repeatability. 

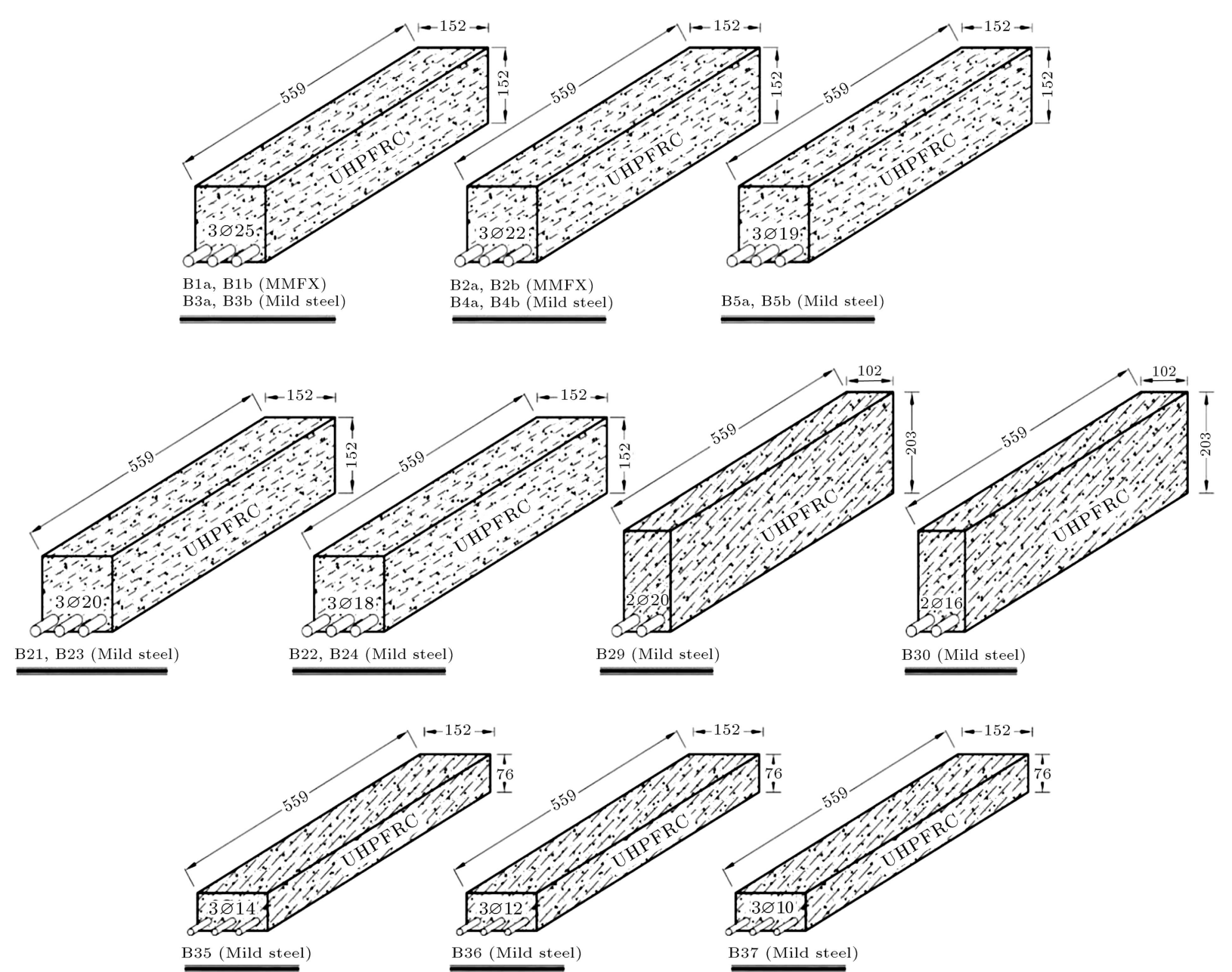

Figure 3. Three-dimensional view of specimens tested by Pourbaba [23] (units are in mm).

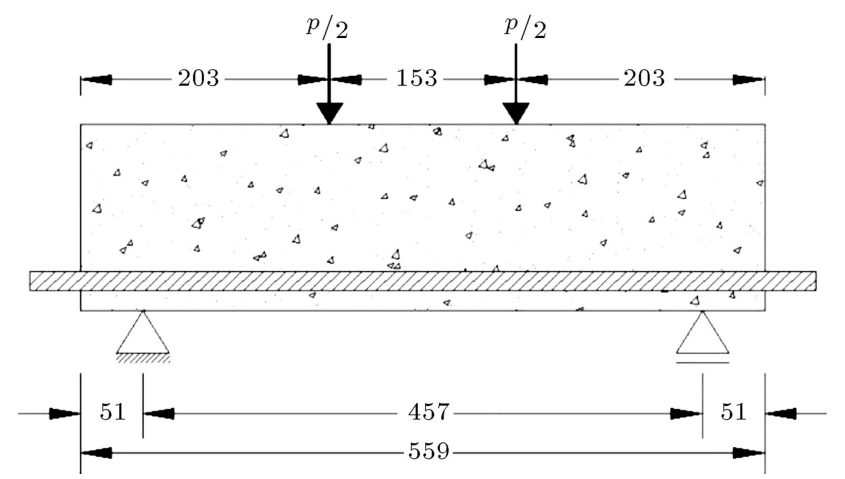

Figure 4. Test setup used by Pourbaba [23] to test UHPC specimens.

the following equation:

$$
V_{c}=\frac{\sqrt{f_{c}^{\prime}}}{6} b_{w} d
$$

where is the specified compressive strength of concrete at age of 28 days, $b_{w}$ is the width of a rectangular beam, and $d$ is the effective depth.

Furthermore, according to ACI Code, $V_{c}$ can go even higher and consequently, be obtained by Eq. (2) in the following, in which the effects of the longitudinal reinforcing as well as the moment and shear magnitudes have been taken into consideration [24,25]:

$$
V_{c}=\left(\sqrt{f_{c}^{\prime}}+120 \rho_{w} \frac{V_{u} d}{M_{u}}\right) \frac{b_{w} d}{7} \leq 0.30 \sqrt{f_{c}^{\prime}} b_{w} d
$$

where $\rho_{w}=A s /\left(b_{w} d\right)$ is the reinforcement ratio and $M_{u}$ is the moment occurring in combination with shear force $V_{u}$ at the cross section considered. Also, according to $\mathrm{ACI}$, in the above equation for $V_{c}, V_{u} d / M_{u}$ shall not be taken greater than unity $[23,24]$. Taking Figure 4 into account, in our case, $V_{u}=P / 2$ and $M_{u}=V_{u} \times a=P a / 2$; consequently, $V_{u} d / M_{u}=d / a$. According to the last column of Table $1, V_{u} d / M_{u}=$ $d / a=1 /(d / a)$ is smaller than 1 , except for B29 and $\mathrm{B} 30$, where the ratios are 1.11 and 1.25 , i.e., marginally above the ACI limit.

Using Eqs. (1) and (2), the shear strength of the beam specimens was determined, of which the results are tabulated in the third and fourth columns of Table 2 . 
Table 2. Maximum experimental shear forces and predicted shear forces using various codes.

\begin{tabular}{|c|c|c|c|c|c|c|c|}
\hline \multirow{3}{*}{ Specimens } & \multirow{3}{*}{$\begin{array}{l}\text { Ultimate } \\
\text { shear } \\
\text { strength* }^{*} \\
\quad(\mathrm{kN})\end{array}$} & \multicolumn{6}{|c|}{ Predicted shear strength $(\mathrm{kN})$} \\
\hline & & \multicolumn{2}{|c|}{ ACI } & \multirow[t]{2}{*}{ RILEM* } & \multirow{2}{*}{$\begin{array}{l}\text { Australian } \\
\text { guideline }\end{array}$} & \multicolumn{2}{|c|}{$\begin{array}{c}\text { Iranian national } \\
\text { building regulations }\end{array}$} \\
\hline & & Eq. (1) & Eq. (2) & & & Eq. (12) & Eq. (13) \\
\hline B1a & 416 & 37 & 52 & 103 & 123 & 27 & 40 \\
\hline $\mathrm{B} 1 \mathrm{~b}$ & 476 & 37 & 52 & 103 & 123 & 27 & 40 \\
\hline $\mathrm{B} 2 \mathrm{a}$ & 468 & 37 & 48 & 104 & 125 & 27 & 37 \\
\hline $\mathrm{B} 2 \mathrm{~b}$ & 436 & 37 & 48 & 104 & 125 & 27 & 37 \\
\hline B3a & 462 & 37 & 52 & 103 & 123 & 27 & 40 \\
\hline $\mathrm{B} 3 \mathrm{~b}$ & 357 & 37 & 52 & 103 & 123 & 27 & 40 \\
\hline B4a & 367 & 37 & 48 & 104 & 125 & 27 & 37 \\
\hline B4b & 388 & 37 & 48 & 104 & 125 & 27 & 37 \\
\hline B $5 \mathrm{a}$ & 402 & 38 & 45 & 105 & 126 & 27 & 34 \\
\hline B $5 b$ & 383 & 38 & 45 & 105 & 126 & 27 & 34 \\
\hline B21 & 349 & 36 & 44 & 86 & 125 & 26 & 34 \\
\hline B22 & 332 & 36 & 42 & 87 & 126 & 26 & 33 \\
\hline B23 & 335 & 36 & 44 & 86 & 125 & 26 & 34 \\
\hline B24 & 336 & 36 & 42 & 87 & 126 & 26 & 33 \\
\hline B29 & 409 & 34 & 40 & 81 & 117 & 24 & 31 \\
\hline B30 & 342 & 34 & 36 & 82 & 118 & 25 & 28 \\
\hline B35 & 106 & 15 & 16 & 37 & 53 & 11 & 12 \\
\hline B36 & 85 & 16 & 16 & 37 & 54 & 11 & 12 \\
\hline B37 & 71 & 16 & 15 & 38 & 55 & 11 & 12 \\
\hline
\end{tabular}

* Based on data from Pourbaba's dissertation [23].

\subsubsection{RILEM TC 162-TDF (test and design methods} for steel fiber reinforced concrete)

The residual flexural tensile strength $f_{R, i}$ is defined as an important parameter, which characterizes the post cracking behavior of steel fiber reinforced concrete. To achieve this property, three-point bending test on notched beams, according to EN 14651 (2005) [26], was conducted by Pourbaba the results of which are used in the current research [23].

The methods of conducting the above-mentioned test have been discussed in some sources such as RILEM TC 162-TDF recommendation (2003) [27], EN 14651 (2005) [26], and fib model code for concrete structures 2010 [28].

The three-point bending test on notched prisms was conducted in accordance with EN 14651(2005) to determine the post-cracking behavior under tension and used to predict shear resistance of the beams without shear reinforcement. The specimens had a height of $150 \mathrm{~mm}$, a width of $150 \mathrm{~mm}$, a span of $500 \mathrm{~mm}$, and a length of $550 \mathrm{~mm}$ with an initial notch of $25 \mathrm{~mm}$ in the middle [23].

According to RILEM TC 162-TDF (2003), the residual flexural tensile strengths $f_{R, 1}$ and $f_{R, 4}$ are respectively defined at $0.5 \mathrm{~mm}$ and $3.5 \mathrm{~mm}$ crack mouth opening displacements and can be determined by means of the following expression:

$$
f_{R, i}=\frac{3 F_{R, i} \times L}{2 b \times h_{s p}^{2}} \quad \mathrm{~N} / \mathrm{mm}^{2},
$$

where $b$ is the width of the specimen, $h_{s p}$ is the distance between the tip of the notch and the top of the cross section, and $L$ is the span of the specimen all in $\mathrm{mm}$.

Hence, the following RILEM TC TDF-162 (2003) equations (standard method) have been used to obtain the nominal shear strength of UHPC beams [14,27]:

$$
\begin{aligned}
& V_{u}=V_{c}+V_{f}+V_{s}, \\
& V_{c}=V_{\text {concrete }}=\left[0.12 k\left(100 \rho_{l} f_{f c k}\right)^{1 / 3}+0.15 \sigma_{c p}\right] b_{w} d, \\
& V_{f}=V_{\text {fibers }}=0.7 k_{f} k \tau_{f d} b_{w} d,
\end{aligned}
$$

where:

$$
\begin{aligned}
& k=1+\sqrt{\frac{200}{d}} \leq 2, \quad \rho_{l}=\frac{A_{s}}{b_{w} d} \leq 0.02, \\
& \tau_{f d}=0.12 f_{R k, 4},
\end{aligned}
$$


where $k_{f}$ is for $T$-sections and $A_{s}$ is the tension reinforcement in the section considered in $\mathrm{mm}^{2}, b$ and $d$ are respectively the section width and the effective depth in $\mathrm{mm}$, and $V_{s}$ is contribution of the shear reinforcement due to stirrups, which in our case was equal to 0.

\subsubsection{Australian design guidelines for ductal prestressed concrete beams}

According to the Australian design guidelines for ductal prestressed concrete beams [29], the following formula gives the shear strength of a prestressed concrete section:

$$
V_{u}=V_{u c}+V_{u s}+P_{v},
$$

where $V_{u c}$ is the contribution of the concrete to the shear strength, $V_{u s}$ is the contribution of the transverse shear reinforcement, and $P_{v}$ is the transverse component of the prestressing force.

When shear reinforcement and inclined tendons are absent, for pretensioned beams, the shear strength is determined from:

$$
V_{u}=V_{u c}
$$

The shear strength of UHPC in beams depends on limiting the principal tensile stress at the centroidal axis or at the junction of the web and flange to a maximum value based on the uncracked section in flexure. This maximum value is given in the following equations $[7,29]$ :

$$
\begin{aligned}
& v_{c}=5.0+0.13 \sqrt{f_{c}^{\prime}}, \\
& V_{c}=v_{c} b_{w} d .
\end{aligned}
$$

The results are tabulated in the sixth column of Table 2 .

\subsubsection{Iranian national building regulations (design and construction of concrete structures)}

The following equations are suggested by Iranian national building regulations to predict the nominal shear strength and shear stress:

$$
\begin{aligned}
& V_{c}=v_{c} b_{w} d, \\
& v_{c}=0.2 \phi_{c} \sqrt{f_{c}},
\end{aligned}
$$

where $b_{w}$ and $d$ are the width of rectangular beam section and effective depth, respectively; $v_{c}$ is the nominal shear stress; and $\phi_{c}$ is the safety factor for concrete that equals 0.60 . Also, $f_{c}$ is the 28-day compressive strength of concrete (standard cylinder strength).

Moreover, there is another equation in the Iranian national building regulations (design and construction of concrete) for concrete beams subjected to shear combined with bending:

$$
V_{c}=\left(0.95 v_{c}+12 \rho_{w} \frac{V_{u} d}{M_{u}}\right) b_{w} d,
$$

where $\rho_{w}$ is the reinforcement ratio and $\rho_{w}=$ $A_{s} /\left(b_{w} d\right)$; also, $M_{u}$ is the moment occurring in combination with shear force $V_{u}$ at the cross section. Similar to ACI code, the Iranian National Building Regulations limit the value of $\frac{V_{u} d}{M_{u}}$ to 1.0. In addition, the Iranian Building Regulation require that $V_{c}$ should be equal to or less than $1.75 v_{c} b_{w} d[30]$. In our case, when considering the overview of beam and applied loads shown in Figure $4, V_{u}=P / 2$ and $M_{u}=V_{u} \times a=P a / 2$ ( $a$ is shear span of specimens); therefore, $V_{u} d / M_{u}=$ $d / a$.

\section{Results and discussions}

Table 2 indicates the maximum shear load recorded $(P / 2)$ during the testing of the specimens [23]. Also, it presents the predicted shear loads, which were determined by applying ACI, RILEM, Australian, and Iranian equations.

As Table 2 and Figure 5 point out, all predicted shear strengths using various models (ACI, RILEM, Australian, and Iranian equations) are less than the experimental shear forces. In Figure 5, the shear strength from testing the experiments is plotted versus its estimated value by each code. The $45^{\circ}$ line drawn from the origin shows the points for a hypothetical situation where experiment and code prediction could determine the same shear strength. As can be seen, all the points are above the $45^{\circ}$ line. This means that all the codes have underestimated the shear capacity for all the specimens. Studying more details

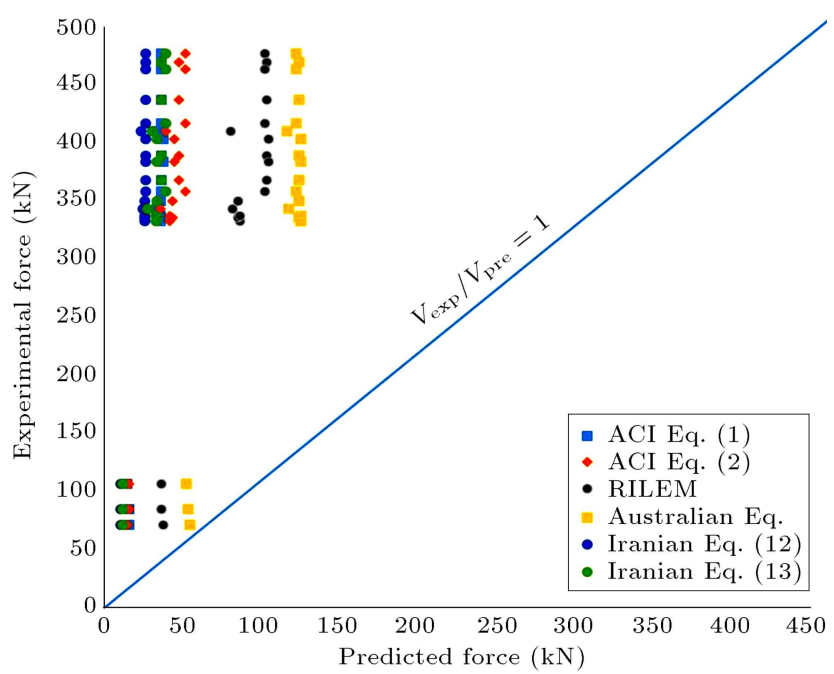

Figure 5. Experimental shear force versus predicted shear strength of existing predictive models for each specimen. 
Table 3. Ratios of experimental shear strength to predicted shear force using various codes.

\begin{tabular}{|c|c|c|c|c|c|c|}
\hline \multirow{3}{*}{ Specimens } & \multicolumn{6}{|c|}{$V_{\text {exp }} / V_{\text {pre }}$} \\
\hline & \multicolumn{2}{|c|}{ ACI } & \multirow{2}{*}{ RILEM } & \multirow{2}{*}{$\begin{array}{c}\text { Australian } \\
\text { guideline }\end{array}$} & \multicolumn{2}{|c|}{ Iranian regulation } \\
\hline & Eq. (1) & Eq. (2) & & & Eq. (12) & Eq. (13) \\
\hline B1a & 11.2 & 8.0 & 4.0 & 3.4 & 15.4 & 10.4 \\
\hline $\mathrm{B} 1 \mathrm{~b}$ & 12.9 & 9.2 & 4.6 & 3.9 & 17.6 & 11.9 \\
\hline $\mathrm{B} 2 \mathrm{a}$ & 12.6 & 9.8 & 4.5 & 3.7 & 17.3 & 12.6 \\
\hline $\mathrm{B} 2 \mathrm{~b}$ & 11.8 & 9.1 & 4.2 & 3.5 & 16.1 & 11.8 \\
\hline B3a & 12.5 & 8.9 & 4.5 & 3.8 & 17.1 & 11.6 \\
\hline B3b & 9.6 & 6.9 & 3.5 & 2.9 & 13.2 & 8.9 \\
\hline B4a & 9.9 & 7.6 & 3.5 & 2.9 & 13.6 & 9.9 \\
\hline $\mathrm{B} 4 \mathrm{~b}$ & 10.5 & 8.1 & 3.7 & 3.1 & 14.4 & 10.5 \\
\hline B5a & 10.6 & 8.9 & 3.8 & 3.2 & 14.9 & 11.8 \\
\hline $\mathrm{B} 5 \mathrm{~b}$ & 10.1 & 8.5 & 3.6 & 3.0 & 14.2 & 11.3 \\
\hline B21 & 9.7 & 7.9 & 4.1 & 2.8 & 13.5 & 10.3 \\
\hline B22 & 9.2 & 7.9 & 3.8 & 2.6 & 12.7 & 10.2 \\
\hline B23 & 9.3 & 7.6 & 3.9 & 2.7 & 12.9 & 9.8 \\
\hline B24 & 9.3 & 8.0 & 3.9 & 2.7 & 12.9 & 10.3 \\
\hline B29 & 12.1 & 10.3 & 5.1 & 3.5 & 16.8 & 13.3 \\
\hline B30 & 10.0 & 9.4 & 4.2 & 2.9 & 13.9 & 12.1 \\
\hline B35 & 6.9 & 6.7 & 2.9 & 2.0 & 9.6 & 8.5 \\
\hline B36 & 5.5 & 5.5 & 2.3 & 1.6 & 7.6 & 7.0 \\
\hline B37 & 4.5 & 4.7 & 1.9 & 1.3 & 6.2 & 6.0 \\
\hline Average & 9.9 & 8.0 & 3.8 & 2.9 & 13.7 & 10.4 \\
\hline
\end{tabular}

reveals that the Australian guideline has given the closest predictions to the experimental results, while the Iranian national building regulations have made predictions very conservatively, as there is a large and wide gap between the predicted shear strength and the shear force obtained from tests.

Table 3 presents the ratios of maximum experimental shear strength to predicted shear force for all the tested specimens using ACI, RILEM, Australian, and Iranian equations, separately. Table 3 also shows the average of the above-mentioned results obtained from each guideline, separately.

As can be seen in Table 3, the minimum average of the experimental shear forces to the predicted shear strength is 2.9, which belongs to Australian guideline. This shows that the Australian guideline is reasonably conservative. The minimum $V_{\exp } / V_{\text {pre }}$ ratio among all the specimens is 1.3 , which also belongs to the Australian guideline, for the B37 specimen. Moreover, the second nearest prediction belongs to RILEM results, which are just slightly conservative in comparison with ACI and Iranian equations that are extremely conservative. This is due to the fact that unlike in the ACI and Iranian regulations, in the Australian guideline and RILEM design methods, the effect of steel fiber reinforcement contribution has been taken into consideration.

The average predictions of the first equation of
ACI Code (Eq. (1)) (column 2 of Table 3) and the first equation of Iranian regulations (Eq. (12)) (column 7 of Table 3), which do not consider the effects of longitudinal reinforcement, and moment and shear magnitudes, are greater and more conservative than the predictions of other equations in the same codes (Eq. (2) and Eq. (13)). This shows that equations taking into account the effect of moment and shear as well as longitudinal reinforcement give better predictions than others do.

Figure 6 indicates the average values of $V_{\exp } / V_{\text {pre }}$ for all the specimens using various codes and reg-

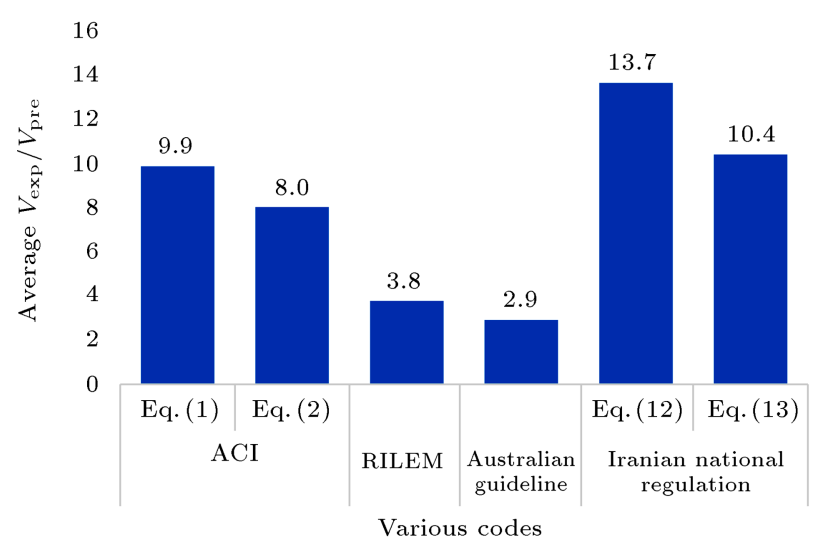

Figure 6. Average ratios of experimental shear strength to predicted shear force obtained by various codes. 
ulations. As clearly illustrated by the graph, the Australian guideline gives the nearest prediction ratio with the value of 2.9. It is followed by RILEM design methods with an average of 3.8 , while the third closest prediction belongs to ACI code with 8.0 and 9.9 corresponding to its two different equations. Finally, the greatest ratio of experimental to predicted shear strength is for the Iranian national building regulations with 10.4 and 13.7 for its two various equations.

\section{Conclusions}

The predicted shear strength of ultra-high performance concrete rectangular beams using various international codes was studied. The predicted shear strengths were compared with the obtained experimental shear strengths, tested by the authors. Moreover, the ratio of experimental to predicted shear strength was determined by various well-known regulations and the obtained safety factors were compared with each other. Based on the results of this research for the Ultra-High Performance Fiber-Reinforced Concrete (UHPFRC) beams without stirrups, the following conclusions can be drawn:

1. All the predicted shear strengths by using various models, including ACI, RILEM TC 162-TDF, Australian guideline (design guidelines for ductal prestressed concrete beams), and Iranian national building regulations (design and construction of concrete structures), are less than experimental maximum shear forces. That is, all the codes intend to be on the conservative side when estimating shear strength;

2. According to the results of the predicted shear forces obtained by various codes, design methods, and regulations, for the beams tested, it can be stated that the Australian design method is quite reasonably conservative, while the RILEM TC 162TDF is slightly more conservative; however, the other codes (ACI code and Iranian regulations) are drastically conservative. A reason is that the Australian design method and RILEM consider the effect of fibers, but the other codes do not consider this important parameter; therefore, taking into account the effect of steel fiber reinforcement in the UHPC beams by ACI code and Iranian regulations or providing new codes and guidelines, specifically for ultra-high performance fiber-reinforced concrete structures, seems absolutely essential;

3. On average, for all the tested UHPC beams, the $V_{c}$ obtained by Australian guideline is 2.9 times less than the experimentally obtained $V_{c}$, while the $V_{c}$ obtained by RILEM TC 162-TDF equation is 3.8 times less than the experimentally obtained $V_{c}$. The two ACI equations (Eqs. (1) and (2)) give the experimental to estimated shear strength ratios of 9.9 and 8.0, respectively. These ratios are 13.7 and 10.4 for two approaches of Iranian regulations (Eq. (12) and Eq. (13)), respectively (Figure 6);

4. The predictions of ACI Eq. 1 and Iranian regulations Eq. 13 give almost similar averages of the ratio of experimental shear strength to predicted shear strength (about 10), both of which are quite conservative as compared with the average ratios obtained by application of RILEM and Australian equations.

\section{Acknowledgment}

The authors are very grateful for the supports provided by the higher education committee of Sharif University of Technology, Kish Island Branch, Iran, during the $\mathrm{PhD}$ studies of the first author of the paper. Also, a number of the tests were conducted at Tabriz University, Iran, and the authors would appreciate this collaboration. The authors would like to thank Dr. Mirmiran; Provost; Lindsey, Professor at the University of Texas, Tyler, TX, US, for the valuable supervision he provided for the first author of the paper; and M. Pourbaba, for his collaboration in conducting a number of tests at his former institution, Florida International University, Miami, FL, US, during his sabbatical leave.

\section{References}

1. Bazant, Z.P. and Kazemi, M.T. "Size effect on diagonal shear failure of beams without stirrups", ACI Structural Journal, 88(3), pp. 268-276 (1991).

2. Voo, Y.L., Poon, W.K., and Foster, S.J. "Shear strength of steel fibre-reinforced ultrahigh-performance concrete beams without stirrups", Journal of Structural Engineering, ASCE, 136(11), pp. 1393-1400 (2010).

3. Graybeal, B.A. "Characterization of the behavior of ultra-high performance concrete", Ph.D. Dissertation, Dept. of Civil and Environmental Engineering, University of Maryland, College Park, Maryland (2005).

4. Graybeal, B.A. "Structural behavior of Ultra-high performance concrete prestressed I girders", FHWA, U.S. Department of Transportation, Report No. FHWAHRT-06-115 (2006).

5. Graybeal, B.A. "Structural behavior of a prototype Ultra-high performance concrete Pi-girder", FHWA, U.S. Department of Transportation, Report No. FHWA-HRT-10-027 (2009).

6. Zohrevand, P. and Mirmiran, A. "Cyclic behavior of hybrid columns made of ultra high performance concrete and fiber reinforced polymers", Journal of Composites for Construction 16.1, ASCE, pp. 91-99 (2012). 
7. Graybeal, B.A. "Ultra-high performance concrete: A state-of-the-art report for the bridge community", FHWA, U.S. Department of Transportation, Report No. FHWA-HRT-13-060 (2013).

8. Meade, T.M. and Graybeal, B.A. "Flexural response of lightly reinforced ultra-high performance concrete beams", Proceedings of the Third International fib Congress and Exhibition Incorporating the PCI Annual Convention and National Bridge Conference, Washington, DC (2010).

9. Steinberg, E. and Reeves, E. "Structural reliability of UHPC bridge girders in flexure", Proceedings of the PCI National Bridge Conference, Atlanta, GA (2004).

10. Stürwald, S. and Fehling, E. "Design of reinforced UHPFRC in flexure", Proceedings of Hipermat 2012 3rd International Symposium on UHPC and Nanotechnology for High Performance Construction Materials, Schmidt, M., Fehling, E., Glotzbach, C., Fröhlich, S., and Piotrowski, S., Eds., Kassel University Press, Kassel, Germany, pp. 443-450 (2012).

11. Visage, E.T., Perera, K.D.S.R., Weldon, B.D., Jauregui, D.V., Newtson, C.M., and Guaderrama, L. "Experimental and analytical analysis of the flexural behavior of UHPC beams", In Proceedings of Hipermat 2012, 3rd International Symposium on UHPC and Nanotechnology for High Performance Construction Materials, Ed., Schmidt, M., Fehling, E., Glotzbach, C., Fröhlich, S., and Piotrowski, S., Kassel University Press, Kassel, Germany, pp. 403-410 (2012).

12. Baby, F., Billo, J., Renaud, J.C., Massotte, C., Marchand, P., and Toutlemonde, F. "Shear resistance of ultra-high performance fibre-reinforced concrete Ibeams", Fracture Mechanics of Concrete and Concrete Structures - High Performance, Fiber Reinforced Concrete, Special Loadings and Structural Applications, Korea Concrete Institute, pp. 1411-1417 (2010).

13. Baby, F., Marchand, P., and Toutlemonde, F. "Shear behavior of UHPFRC beams. I: Experimental investigation", J. Struct. Eng., 140(5), 04013111 (2013).

14. Baby, F., Marchand, P., and Toutlemonde, F. "Shear behavior of UHPFRC beams. II: Analysis and design provisions", J. Struct. Eng., 140(5), 4013112 (2013).

15. Cauberg. N, Pierard, J., and Parmentier, B. "Shear capacity of UHPC-beam tests", Proceedings of Hipermat 2012, 3rd International Symposium on UHPC and Nanotechnology for High Performance Construction Materials, Ed., Schmidt, M., Fehling, E., Glotzbach, C., Fröhlich, S., and Piotrowski, S., Kassel University Press, Kassel, Germany, pp. 451-458 (2012).

16. Fehling, E. and Thiemicke, J. "Experimental investigation on I-shaped UHPC beams with combined reinforcement under shear load", Proceedings of Hipermat 2012, 3rd International Symposium on UHPC and Nanotechnology for High Performance Construction Materials, Schmidt, M., Fehling, E., Glotzbach, C., Fröhlich, S., and Piotrowski, S., Kassel University Press, Kassel, Germany, pp. 477-484 (2012).
17. Hegger, J., Tuchlinski, D., and Komner, B. "Bond anchorage behavior and shear capacity of ultra high performance concrete beams", Proceedings of the International Symposium on Ultra High Performance Concrete, Schmidt, M., Fehling, E., and Geisenhanslüke, C., Eds., Kassel University Press, Kassel, Germany, pp. 351-360 (2004).

18. Hegger, J. and Bertram, G. "Shear carrying capacity of steel fiber reinforced UHPC", Proceedings of the Second International Symposium on Ultra High Performance Concrete, Fehling, E., Schmidt, M., and Stürwald. S., Eds., Kassel University Press, Kassel, Germany, pp. 513-520 (2008).

19. Tompos, E.J. and Frosch, R.J. "Influence of beam size, longitudinal reinforcement, and stirrup effectiveness on concrete shear strength", ACI Structural Journal, 99S57, pp. 559-567 (2002).

20. Kwak, Y.K., Eberhard, M.O., and Kim, J. "Shear strength of steel fiber-reinforced concrete beams without stirrups", ACI Structural Journal, 99-S55, pp. 530-538 (2002).

21. MacGregor, J.G., Reinforced Concrete: Mechanics and Design, In Prentice - Hall Inc., Upper Saddle River, N.J. (1997).

22. Nadim, H. and Al-Manaseer, A. Structural Concrete: Theory and Design, in John Wiley \& Sons, Inc., Hoboken, New Jersey (2015).

23. Pourbaba, M. "Shear capacity of ultra-high performance concrete rectangular beams", PhD Dissertation, Department of Civil Engineering, Sharif University of Technology, International Campus, Kish Island (2017).

24. ACI Committee 318 "Building code requirements for structural concrete (ACI315-05) and commentary (318R-05)", In American Concrete Institute, Farmington Hills, Mich., p. 430 (2005).

25. McCormac, J.C. and Nelson, J.K., Design of Reinforced Concrete, in John Wiley (2005).

26. EN 14651, Test Method for Metallic Fibered ConcreteMeasuring the Flexural Tensile Strength (Limit of Proportionality (LOP), Residual), CEN (European Committee for Standardization), Brussels, Belgium, (2005).

27. RILEM TC 162-TDF "Test and design methods for steel fibre reinforced concrete, final recommendations", Materials and Structures, 36, pp. 560-567 (2003).

28. "fib model code for concrete structures 2010", International Federation for Structural Concrete, Lausanne, Switzerland (2013).

29. Gowripalan, N. and Gilbert, I.R. Design Guidelines for Ductal Prestressed Concrete Beams, School of Civil and Environmental Engineering, The University of NSW, Australia, p. 53 (2000).

30. "Design and construction of concrete structures", Iranian National Building Regulations, Ministry of Roads \& Urban Development, Islamic Republic of Iran, Tehran (2000). 


\section{Biographies}

Masoud Pourbaba obtained his BS and MS degrees in Civil Engineering from Tabriz University and Mazandaran University in 1998 and 2001, respectively. $\mathrm{He}$ is currently a PhD candidate at Sharif University of Technology, International Campus, and has been a faculty member at Islamic Azad University (Maragheh Branch) since 2004. He is also a member of ASCE and ACI. He took a sabbatical leave at Florida International
University to work on UHPC in 2014. His main research interests are focused on UHPC, rehabilitation and retrofitting of structures, and large-scale experimental testing.

Abdolreza Joghataie is a faculty member in Civil Engineering Department at Sharif University of Technology. His research interests include structural health monitoring and optimization, numerical methods, and artificial neural networks. 